\title{
Sedimentation of suspended solids in ultrasound field
}

\author{
Vera Vikulina ${ }^{1 *}$ and Pavel Vikulin ${ }^{1}$ \\ ${ }^{1}$ Moscow State University of Civil Engineering, Yaroslavskoye shosse, 26, Moscow, Russia, 129337
}

\begin{abstract}
Physical and chemical effects of aquatic environment that occur in an ultrasonic field change the sedimentation rate of coagulated suspension. This might only happen in case of cavitation of ultrasonic filed that causes a change of potentials of the medium. Research of the influence of ultrasonic vibrations on coagulation of suspended solids within water purification allows expanding their scope of implementation. The objective of the research is to estimate the effect of ultrasound on the sedimentation of the suspended solids, to determine of the efficiency of the process in relation to the dose of the coagulant, and to calculate the numerical values of the constants in the theoretical equation. The experiment condition was held in the water with the clay substances before the introduction of the coagulant. The method of magnetostriction ultrasonic generator was applied to receive ultrasonic vibration. Estimate of concentration of clay particles in water was performed using photometry. As a result of the research, the obtained data allow determining the increase in efficiency of suspended particles sedimentation related to the dose of coagulant, depending on time of ultrasonic treatment. The experiments confirmed the connection between the effect of sedimentation in the coagulation process, the coagulant dose and the time of scoring. Studies have shown that the increase in the duration of ultrasonic treatment causes a decrease of administered doses of coagulant.
\end{abstract}

Keywords: sedimentation, ultrasound treatment, coagulant

\section{Introduction}

Various physical and chemical effects occur in the ultrasonic field, may be associated with the transformation of energy of elastic vibrations. In this case, we can say that they are one of the types of mechanic and chemical reactions $[1,2]$. These effects are accompanied by the phenomenon of cavitation [2]. On the other hand, elementary processes of sound and chemical reactions that are similar to radiolysis, reactions in electric discharge, and photolysis [3, 4].

Napiers and Nolting put forward the theory of high temperatures occurrence by adiabatic compression of a cavitation bubble [4]. According to their calculations, within continuous increase the velocity of the motion of bubble - liquid boundary temperature in the collapsing bubble can reach $10000^{\circ} \mathrm{K}$, and the pressure in the shock wave up to $10^{4}$ bar. [5]. Such high temperatures occurring in the gas-filled cavity of the bubble, can determine

\footnotetext{
*Corresponding author: nocviv@mgsu.ru
} 
the occurence in it of electric charges of dissociated and ionized molecules, atoms, free radicals [6]. Thus, the this cavity can serve as a source of products with a high reactivity and launch physical and chemical actions in the ultrasonic field.

Soviet physicist Y. I. Frenkel suggested the occurrence on the walls of the formed lenticular cavity electric charges of opposite sign. In the initial stage of formation of a cavity in it there are electric charges. Y. I. Frenkel believes that the break of continuity of the environment in the areas of rarefaction are formed not spherical cavity and lenticular, molecular sizes. For such a gap requires the amplitude of the pressure, of the order of $10^{3}-$ $10^{4}$ bar.

The transition from lenticular to spherical cavity occurs due to penetration of dissolved gases or vapors of surrounding liquid. The schematic structure of a cavity is shown in Fig. 1 [7].

According to the theory of Ya. Frenkel, in conditions of an electric discharge energyrich particles, the ionized molecules and the ions, free radicals arise in the cavity [7].

Considering that the charges formed as a result of the uneven distribution of ions on the walls of the bubble in the fluid gap, Ya. I. Frenkel determined the field strength within the cavity at the time of its formation:

$$
E_{\text {п }}=\frac{4 \bar{e}}{r_{\Pi}} \sqrt{N_{\Pi} \delta_{\Pi}},
$$

$E_{\text {п }}-$ field intensity, [V/cm];

$\delta_{\text {пI }}-$ gap between liquid layers, $[\AA]$;

$N_{\text {п }}$ - the number of dissociated molecules per unit volume;

$r_{\mathrm{\Pi}}-$ the radius of a cavity, $[\mathrm{cm}]$;

$\bar{e}$ - electron charge, $[\mathrm{Cl}]$.

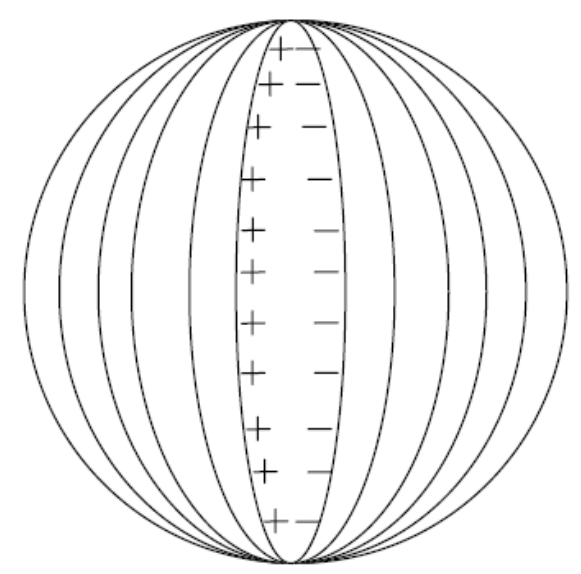

Fig. 1. Cavity structure

R. Parker [8] carried out experimental study of coagulation under the action of ultrasonic vibrations. Experiments were done on the smoke of magnesium oxide in the air. It was observed that in the absence of acoustic field normal coagulation and sedimentation process was negligible. There are examples of use of the coagulating action of ultrasound during the deposition of suspended solids.

At intensities of the order of $0.3-0.5 \mathrm{~W} / \mathrm{cm}^{2}$ ultrasound promotes coagulation of suspended particles. Scoring of a suspension of calcium carbonate (particle size of $47 \mu \mathrm{m})$, quartz dust $(23 \mu \mathrm{m})$ and anthracite $(76-152 \mu \mathrm{m})$ leads to an acceleration of the process of settling. 
Conducted research the possibility of coagulation of high-ash coal slurries with polymers and ultrasound. For experimental studies have used ultrasound generator high pressure (USHP) - 2 frequency range from 0.1 to $10.0 \mathrm{MHz}[9,10]$.

Research conducted in the all-Union scientific research Institute VODGEO at ultrasonic coagulation of finely dispersed systems $\mathrm{L}-\mathrm{S}$ and $\mathrm{L}-\mathrm{L}$ (Hydrosol of iron, activated sludge, polystyrene latex, concentrate copper ore, water, coal tar, etc.) showed that exposure to ultrasound coagulates finely dispersed system with a particle size of from 1 to 5 microns; for the system of $\mathrm{L}-\mathrm{S}$ the best results occur when the frequency of $8-$ to $18 \mathrm{kHz}$, and for systems L - L - at a frequency of $400-800 \mathrm{kHz}$. With the increase of intensity of ultrasonic vibrations increases the effect of coagulation [1]. Observed coagulation liquid systems, for example, an aqueous suspension of $\mathrm{Al}_{2} \mathrm{O}_{3}$ under the action of ultrasound. The experiments showed that already after a few minutes there is a sharp coagulation of the slurry, whereas in normal conditions it is completely absent [11, 12, 13]. Analyzing the above, we can say that the ultrasonic vibrations in the water system can have a significant impact on the processes associated with the oxidation of impurities, the phenomenon of crystallization and coagulation of suspended solids.

It must be emphasized that the desired effect for the above-mentioned process in the ultrasonic field can be achieved only in the presence of cavitation regime in volume. The process by which the ultrasound can have an effect is the coagulation of fine suspended matter in the water [14].

\section{Research aim}

The aim of this work is to conduct research on the sedimentation of the suspended solids in the ultrasonic field and to receive data to verify the theoretical equation $[15,16,17,18]$

$$
\frac{\Delta \mathrm{G}}{\mathrm{G} \cdot \mathrm{q}}=\mathrm{a}+\mathrm{b} \cdot \mathrm{t}
$$

$a$ и $b$ - constants;

$G$ - Clay particles per volume unit $[\mathrm{mg} / \mathrm{l}]$;

$\Delta G$ - suspended clay particles $[\mathrm{mg} / 1]$

$q$ - Coagulant dose, $\left[\mathrm{mg} / \mathrm{l}\right.$ of $\left.\mathrm{Al}_{2} \mathrm{O}_{3}\right]$

$t$-Sound duration, [min].

The objective of the work is to obtain numerical values of constants $a$ and $b$ for theoretical equations (2) and the relative standard deviation (dispersion) [19].

\section{Materials and methods}

The main experiment was the deposition of clay particles with a concentration of $120 \mathrm{mg} / \mathrm{l}$ when added to water coagulant - aluminum salts with a dose of $\mathrm{Al}_{2} \mathrm{O}_{3}-2.5,5.0$, and 10.0 $\mathrm{mg} / \mathrm{l}[20,21]$.

Carried out pre-treatment of water with ultrasound with subsequent introduction of the coagulant. Cavitation mode of ultrasonic field in water was maintained by an ultrasonic generator (ultrasonic generator)-2-4 and a magnetostrictive transducer (ICP) 6-22 (frequency and intensity for excitation in water cavitation $\mathrm{f}=18-22 \mathrm{kHz}, \mathrm{I}=2.0 \mathrm{~W} / \mathrm{cm} 2$ ).

Pre-treatment of water with suspended clay particles was carried out with ultrasound for $0.1 ; 0.5 ; 1.0 ; 2.0$ and 5.0 minutes. Estimation of concentration of clay particles in water was carried out according to standard techniques, the photometric method by comparing samples of the investigated water with standard suspension. 


\section{Results}

To verify the theoretical equation (2) the decrease in the concentration of clay particles suspended in water was determined, as the difference between initial and final concentration (the deposition process is completed). As a value that characterizes the deposition process, the ratio of the decrease in the concentration of $\Delta \mathrm{G}$ to its final value of $\mathrm{G}_{2}$ taken, related to the dose of the coagulant was taken. Experimental data on the effect of ultrasound on the coagulation process placed in the Table 1.

Table 1. Research data

\begin{tabular}{|c|c|c|c|c|c|c|}
\hline No & $\begin{array}{c}\text { Initial SS } \\
\text { concentration } \\
G[\mathrm{mg} / \mathrm{l}]\end{array}$ & $\begin{array}{c}\text { Final SS } \\
\text { concentration } \\
G_{2},[\mathrm{mg} / \mathrm{l}]\end{array}$ & $\begin{array}{c}\text { SS } \\
\text { concentration } \\
\text { decline } \Delta G, \\
{[\mathrm{mg} / \mathrm{l}]}\end{array}$ & $\begin{array}{c}\text { Sound } \\
\text { duration } t, \\
{[\text { [min] }}\end{array}$ & $\begin{array}{l}\text { Coagulant } \\
\text { dose } q, \\
\text { [mg/l] }\end{array}$ & $\frac{\Delta G}{G_{2} q}$ \\
\hline 1 & 120 & 91 & 29 & 0.5 & 2.5 & 0.1 \\
\hline 2 & 120 & 83 & 37 & 1.0 & 2.5 & 0.12 \\
\hline 3 & 120 & 71 & 49 & 2.0 & 2.5 & 0.16 \\
\hline 4 & 120 & 51 & 69 & 5.0 & 2.5 & 0.23 \\
\hline 5 & 120 & 69 & 51 & 0.17 & 5.0 & 0.09 \\
\hline 6 & 120 & 66 & 54 & 0.5 & 5.0 & 0.09 \\
\hline 7 & 120 & 57 & 63 & 1.0 & 5.0 & 0.11 \\
\hline 8 & 120 & 54 & 66 & 2.0 & 5.0 & 0.11 \\
\hline 9 & 120 & 34 & 86 & 5.0 & 5.0 & 0.14 \\
\hline 10 & 120 & 114 & 6 & 0 & 2.5 & 0.023 \\
\hline 11 & 120 & 86 & 34 & 0 & 5.0 & 0.079 \\
\hline 12 & 120 & 31 & 89 & 0 & 10.0 & 0.287 \\
\hline
\end{tabular}

Table 1 shows that, the maximum deposition of clay particles was observed at the dose of coagulant on $\mathrm{Al}_{2} \mathrm{O}_{3}$ equal to $10 \mathrm{mg} / \mathrm{l}$ without ultrasonic treatment, which is MAX level.

When measuring the concentration of suspended solids by the constant value of the instrument was determined, allowing it to switch from the scale to the weight concentration of clay particles in water. It is installed for stationary uniform distribution of particles in a given volume of water, so the colorimeter measured the concentration of particles in the water just before the experiment (initial concentration) and after all flakes settled, and the water was the final (residual) concentration of only one clay particles. All intermediate readings are unable to fix the bleaching process as such, but only indicate the duration of the dynamics of the process.

\section{Results processing}

Statistical analysis of experimental data performed with the goal of finding the coefficients $\mathrm{a}$ and $\mathrm{b}$ in equation (2) and the calculated relative standard deviation (dispersion) values of the experiments [19].

The experimental data on the deposition of suspended solids using the cavitation regime in the ultrasonic field is revealed in table 2. To perform the calculation adopted the following notation: time scoring $t=x_{k}$, the ratio of the concentration of deposited clay particles to a final concentration of suspended solids is related to the dose of coagulant $\frac{\Delta G}{G_{2} q}=y_{k}$. In the calculation, we used the deviations from the arithmetic mean values $\mathrm{k}-$ $\mathrm{x}$ results of the experiments. 
Table 2. Experiment and calculated data

\begin{tabular}{|c|c|c|c|c|c|c|c|}
\hline No & $\boldsymbol{t}=\boldsymbol{x}_{\boldsymbol{k}}$ & $\frac{\Delta G}{G_{2} q}=y_{k}$ & $x=\bar{x}-x_{k}$ & $y=\bar{y}-y_{k}$ & $\boldsymbol{x} \cdot \boldsymbol{y}$ & $\boldsymbol{x}^{\mathbf{2}}$ & $\boldsymbol{y}^{\mathbf{2}}$ \\
\hline 1 & 2 & 3 & 4 & 5 & 6 & 7 & 8 \\
\hline 1 & 0.5 & 0.1 & +1.41 & +0.028 & +0.039 & 1.990 & 0.0008 \\
\hline 2 & 1.0 & 0.12 & +0.91 & +0.008 & +0.007 & 0.828 & 0.00006 \\
\hline 3 & 2.0 & 0.16 & -0.09 & -0.032 & +0.003 & 0.0081 & 0.001 \\
\hline 4 & 5.0 & 0.23 & -3.09 & -0.102 & +0.315 & 9.548 & 0.0104 \\
\hline 5 & 0.17 & 0.09 & +1.74 & +0.038 & +0.0066 & 3.027 & 0.0014 \\
\hline 6 & 0.5 & 0.09 & +1.41 & +0.038 & +0.054 & 1.988 & 0.0014 \\
\hline 7 & 1.0 & 0.11 & +0.91 & +0.018 & +0.016 & 0.828 & 0.00032 \\
\hline 8 & 2.0 & 0.11 & -0.09 & +0.018 & -0.002 & 0.0081 & 0.00032 \\
\hline 9 & 5.0 & 0.14 & -3.09 & -0.012 & +0.037 & 9.548 & 0.00014 \\
\hline$\sum$ & 17.17 & 1.15 & & & 0.535 & 27.77 & 0.0164 \\
\hline Av. value & 1.91 & 0.128 & & & 0.0594 & & \\
\hline
\end{tabular}

The calculation was made under the formula:

$$
\mathrm{K}_{\mathrm{xy}}=\sum_{\mathrm{k}=1}^{\mathrm{n}} \mathrm{x}_{\mathrm{k}} \mathrm{y}_{\mathrm{k}}-\overline{\mathrm{xy}} \text {, }
$$

At the same time the coordinates of all experimental points, subtract the coordinates of a point located in the middle region [19]. The correlation coefficient is determined by the formula:

$$
r=\frac{\overline{x y}}{\sigma_{x} \sigma_{y}}
$$

$\sigma_{x}$ and $\sigma_{y}-$ the standard deviation.

For calculating the dispersion the formula was used:

$$
\sigma_{x}^{2}=\frac{1}{n} \sum_{k=1}^{n} x_{k}-\bar{x}^{2} \text { и } \sigma_{y}^{2}=\frac{1}{n} \sum_{k=1}^{n} y_{k}-\bar{y}^{2}
$$

We substitute the experimental data and calculated values for $\mathrm{x}$ :

$$
\sigma_{x}^{2}=\frac{27.77}{9}=3.09, \quad \sigma_{x}=\sqrt{3.09}=1.76
$$

And for $y$ as well:

$$
\sigma_{y}^{2}=\frac{0.0164}{9}=0.00182, \quad \sigma_{y}=\sqrt{0.00182}=0.0425
$$

Then we find the correlation coefficient

$$
\mathrm{r}=\frac{0.0594}{1.76 \cdot 0.0426}=0.79
$$

We use the general expression (9) to estimate the coefficients for equation (2)

$$
y-\bar{y}=\frac{\sum x y}{x^{2}} x-\bar{x} .
$$

Made for the $y$ (ordinate), and it was postponed the value of the expression $\frac{\Delta G}{G_{2} \cdot q}$ and on the $\mathrm{x}$-axis (abscissa) expression of the form $\mathrm{x}=\mathrm{t}$, we can write

$$
\frac{\Delta \mathrm{G}}{\mathrm{G}_{2} \cdot \mathrm{q}}-\overline{\mathrm{y}}=\frac{\Sigma \mathrm{xy}}{\mathrm{x}^{2}} \cdot \mathrm{t}-\mathrm{x} \text {. }
$$


By substituting the obtained numerical values of the expression (10) takes the form

$$
\frac{\Delta \mathrm{G}}{\mathrm{G}_{2} \cdot \mathrm{q}}-0.128=\frac{0.535}{27.7} \cdot \mathrm{t}-1.91
$$

The solution of equation (11) we get equation (12):

$$
\frac{\Delta \mathrm{G}}{\mathrm{G}_{2} \cdot \mathrm{q}}=0.03 \cdot \mathrm{t}+0.071
$$

The resulting equation (12) substituted the values of $\mathrm{t}$ and calculated ratio $\frac{\Delta G}{G_{2} q}$, the results of which are shown in Table 3.

Table 3. The results of calculations of the duration of ultrasonic treatment from 0 to 5 minutes

\begin{tabular}{|c|c|c|c|c|c|}
\hline$t[\mathrm{~min}]$ & 0 & 1 & 2 & 3 & 5 \\
\hline$\frac{\Delta \mathrm{G}}{\mathrm{G}_{2} \cdot \mathrm{q}}$ & 0.071 & 0.101 & 0.131 & 0.161 & 0.221 \\
\hline
\end{tabular}

The graphic description of the data obtained (Table 1, Table 2 and Table 3 ) is shown in Fig. 2: experimental and theoretical values; theoretical line; MAX level; area of maximum dispersion, equal to $3 \sigma$.

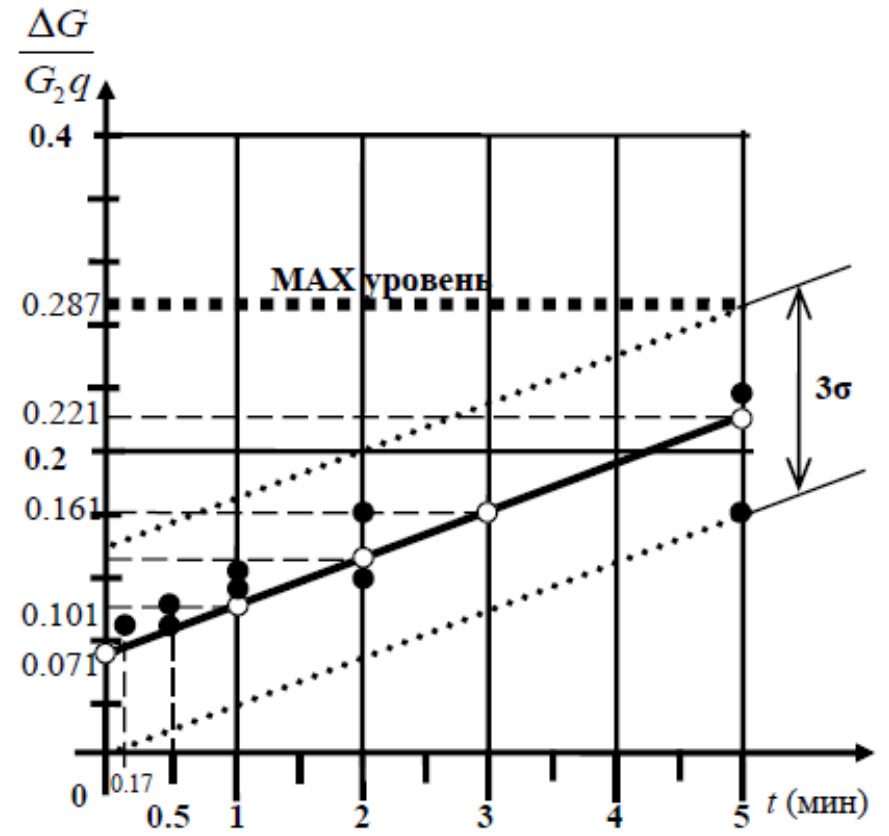

Fig. 2. Diagram of change of the relative content of suspended solids in the water treated with the coagulant, duration of ultrasound exposure: $\bigcirc-$ theoretical points, $\bullet-$ experiment points

On the chart of Fig. 2 values $\frac{\Delta G}{G_{2} q}$ plotted depending on the time of the $\mathrm{t}$ sound.

Treatment of water containing suspended solids, ultrasound, in all cases, remained provisional, i.e. until the introduction of coagulant, as it was supposed earlier about the possible effect of ultrasonic vibrations on suspended solids.

There is a horizontal dotted line plotted on the graph passing through the value 
$\frac{\Delta G}{G_{2} q}=0.287$, which shows the maximum level at the dose of coagulant of $10 \mathrm{mg} / \mathrm{l}$ on $\mathrm{Al}_{2} \mathrm{O}_{3}$ (without sound, Table 1).

As can be seen from the graph of Fig. 2, the experimental points lie in the area of possible spread, equal to $3 \sigma$. Thus, confirmed the assumption of the description of phenomena of coagulation using ultrasound to equation (2).

\section{Conclusions}

1) Experimental studies have confirmed the assumptions about the changing potentials of the suspended particles in the water, because of the action of ultrasonic field.

2) Change of potential under the action of ultrasound leads to an increase of the effect of deposition.

3) Determined the numerical values of the constants a and b of the theoretical equation (2).

4) Statistical processing of experimental data allowed obtaining the area variation equal to $3 \sigma$.

5) The experiments confirmed the relationship between values:

- The duration of the sound;

- The dose of coagulant;

- Effect of deposition in the coagulation process.

6) Increase the duration of ultrasonic treatment leads to a reduction of administered doses of coagulant.

7) Experimental studies and calculations have shown that the effect of deposition of suspended solids in water, time-dependent scoring and coagulant dosage increased three times.

\section{References}

1. P. D Vikulin. Physical and chemical manifestation of the acoustic field in the technologies of water conditioning. (2004).

2. I. P. Golyamina, Ultrasound. Little encyclopedia of Moscow (1979).

3. V. Vikulina, P. Vikulin.. Water treatment coagulation under the action of ultrasonic field (2016)

4. M. G. Sirotyuk, Acoustic cavitation (2008).

5. M. A. Margulis, Adv. In Phys. Sci. 170 (3), 263-287. (2000).

6. K. Hill, J. Bamber, H. Ter Haar, Ultrasound in medicine. The physical basis for the use (2008).

7. N. Makisha, Pr. Eng., 165, 1087-1092 (2016)

8. Y. Zhou, L. Zhai, L., R. Simmons, P. Zhong, J. Acoust. Soc. Am. 2 (120), 676-685 (2006)

9. N. Makisha, I. Panteleeva, MATEC Web of Conferences, 106, 70015 (2017)

10. L. R. Gavrilov, Focussed high intensity ultrasound in medicine (2013)

11. V. V. Zavyalov, Study of electrocoagulation purification of drinking waters (2004)

12. T. G. Leighton, The Acoustic Bubble (1994)

13. Edited by Y. Mason, Physical acoustics. part 1 (1967)

14. V. B. Vikulina, The use of ultrasonic vibrations for the processes of softening of water and deposition of suspended matter (1980)

15. E. V. Alekseev and others, Fundamentals of water systems modeling (2015) 
16. P. D. Vikulin, V. B. Vikulina, Hydraulics of water Supply and Sanitation. Second edition (2015)

17. N. Makisha, Pr. Eng., 165, 1092-1097 (2016)

18. V. B. Vikulina, P. D. Vikulin, Water treatment coagulation under the action of ultrasonic field (2016)

19. E. S. Wentzel, The theory of probability. Tenth edition, (2005)

20. V. B. Vikulina, P. D. Vikulin, The use of ultrasound in coagulation (2016)

21. B. D. Summ, Foundations of colloid chemistry (2007) 